\title{
A REPRESENTAÇÃO DA MULHER NA ICONOGRAFIA DE ÁJAX CARREGANDO O CORPO DE AQUILES NA PINTURA DA CERÂMICA ÁTICA (570-480 a.C.)
}

\author{
The representation of women in the iconography \\ of Ajax carrying the body of Achilles in \\ Attic pottery painting (570-480 BC)
}

José Geraldo Costa Grillo*

\begin{abstract}
RESUMO
Da perspectiva dos estudos de gênero, a representação da mulher na pintura da cerâmica ática tem sido entendida basicamente de duas maneiras: 1) os pintores revelam o mesmo preconceito discriminatório encontrado nos textos literários; 2) tanto nos textos quanto na iconografia, a posição social da mulher não é assim estanque. Partilhando dessa segunda concepção, o autor demonstra, a partir da análise iconográfica da cena de Ájax carregando o corpo de Aquiles, que se, por um lado, a mulher, por vezes, desempenha um papel secundário, podendo implicar sua desvalorização social, por outro ocupa, em inúmeros e significativos casos, o lugar central como protagonista do evento, demonstrando seu prestígio e valor aos olhos de sua sociedade.
\end{abstract}

Palavras-chave: mulher; gênero; pintura; cerâmica ática; iconografia.

\begin{abstract}
From the perspective of gender studies, women's representation in painting Attic pottery has been understood primarily in two ways: 1) painters show the same discriminatory bias found in literary texts, 2) in both literary texts, and iconography, the social position of women is not so tight. Sharing this second conception, the author demonstrates
\end{abstract}

\footnotetext{
Professor do Departamento de História da Arte da UNIFESP. O autor agradece ao apoio institucional da UNIFESP e da CAPES e aos professores Pedro Paulo Abreu Funari (UNICAMP), Renata Senna Garrafoni (UFPR), François Lissarrague (EHESS), Haiganuch Sarian (MAE-USP) e Pauline Schmitt-Pantel (PARIS 1). As ideias são de sua inteira responsabilidade.
} 
from the iconographic analysis of the scene of Ajax carrying the body of Achilles that, on the one hand, she sometimes plays a secondary role, implying their social devaluation, on the other hand, occupies in numerous and significant cases, the central place as the protagonist of the event, demonstrating its prestige and value in the eyes of their society.

Keywords: women; gender; painting; Attic pottery; iconography.

\section{Introdução}

No interior do processo de revisões e mudanças epistemológicas pelo qual vêm passando as Ciências Humanas, a História da Arte tem experimentado mudanças que renovaram suas temáticas, teorias e metodologias. As análises iconográfica e iconológica, por exemplo, continuam a ser usadas, mas não mais sozinhas, pois as ideias geradas por elas são agora tomadas como ponto de partida para se colocar questões relacionadas à ideologia, à classe, ao gênero, ao colonialismo, etc., que trazem consigo teorias contextuais específicas. ${ }^{1} \mathrm{Na}$ História da Arte Antiga, gênero, etnicidade e poder emergiram como tópicos destacados em sua pesquisa recente. ${ }^{2}$ No que concerne à Arte Grega, além das análises formal e estilística, surgiu o interesse pela questão de como a figuração de um determinado personagem pode contribuir para a compreensão das relações de gênero, das posições social e étnica dentro de sua cultura. ${ }^{3}$

Da perspectiva dos estudos de gênero, ${ }^{4}$ a representação da mulher na pintura da cerâmica ática tem sido entendida basicamente de duas maneiras, que não são completamente excludentes. Dyfri Williams, em um estudo dedicado aos problemas de interpretação da representação da mulher,

2005 .

1 Cf. D'AlleVA, Anne. Methods and theories of Art History. London: Laurence King,

2 Cf. DONOHUE, Alice A. Introduction. In: ; FULLERTON, Mark D. (Eds.). Ancient art and its historiography. Cambridge: Cambridge University, 2003, p. 1-12.

3 Cf. STANSBURY-O'DONNELL, Mark D. Looking Greek art. Cambridge: Cambridge University, 2011.

4 Para as teóricas e metodológicas relacionadas aos estudos de gênero na Antiguidade Clássica, cf. BOEHRINGER, Sandra; SEBILLOTTE CUCHET, Violaine (Dirs.). Hommes et femmes dans l'Atiquité grecque et romaine - Genre: méthode et documents. Paris: Armand Colin, 2011. 
entende, por um lado, que a pintura desses vasos foi feita, essencialmente, a partir de uma visão masculina, na qual as atitudes sociais referentes às mulheres ecoam o preconceito preservado em outras fontes históricas. ${ }^{5}$ François Lissarrague, trabalhando também com uma série de vasos áticos, afirma, por outro lado, ter tido a mulher ateniense desse período uma participação mais efetiva na guerra. Lissarrague destaca, quanto a isso, que, nas cenas de armamento, o lugar das mulheres é mais importante do que os documentos escritos nos fazem supor. Pois, frequentemente, é uma mulher que se encontra diante do guerreiro entregando-lhe sua armadura, o que significa que guerra não é um simples negócio de homens, ela concerne à cidade inteira, ela implica a participação das mulheres. ${ }^{6}$

Partilhando dessa segunda concepção, analiso a iconografia de Ájax carregando o corpo de Aquiles na pintura da cerâmica ática, com a finalidade de demonstrar que se, por um lado, a mulher é, por vezes, representada em um papel secundário, podendo implicar sua desvalorização social, por outro ocupa, em inúmeros e significativos casos, o lugar central como protagonista do evento, demonstrando seu prestígio e valor aos olhos de sua sociedade.

De modo a cumprir este objetivo, apresento primeiramente a história da pesquisa deste tema, para que fique claro com que dialogo e de onde parto; em seguida, realizo a análise iconográfica, que se constitui na base de minha argumentação; e, por fim, teço as considerações finais, sintetizando os resultados obtidos.

\section{História da pesquisa}

O primeiro estudo sistemático da iconografia de Ájax carregando o corpo de Aquiles foi realizado por Susan Woodford, que abordou sessenta e um vasos áticos e os dividiu em nove grupos iconográficos, conforme os

5 WILLIAMS, Dyfri. Women on Athenian vases: problems of interpretation. In: CAMERON, Averil; KUHRT, Amélie (Eds.). Images of women in Antiquity. London: Routledge, 1983, p. 92-106.

6 LISSARRAGUE, François. Femmes au figuré. In: DUBY, Georges; PERROT, Michelle (Dirs.). Histoire des femmes en occident. Volume 1, L'Antiquité. Sous la direction de Pauline Schmitt Pantel. Paris: Plon, 1991, p. 159-251. 
personagens representados. ${ }^{7}$ Esses grupos compõem dois contextos básicos, nos quais a morte de Aquiles é representada: a guerra na qual morreu e a família que deixou enlutada. Quando Ájax e Aquiles estão sozinhos ou acompanhados de outros guerreiros, trata-se do contexto da guerra (Grupos A-B e G); e quando, além dos personagens anteriores, há outros, como mulher e idoso, trata-se do contexto familiar (Grupos C-F e H). ${ }^{8}$

O contexto da guerra foi o primeiro a ser representado. De início, Woodford destaca que o tema de um guerreiro carregando seu companheiro morto do campo de batalha remete a uma apreciada tradição heroica. Representações desse tema aparecem desde o período geométrico recente, sem especificar, todavia, a identidade dos dois guerreiros. O Pintor Clítias, por volta de 570 a.C, foi o primeiro a fazer isso, nomeando, com inscrições, Ájax e Aquiles. Ájax movimenta-se à direita, com Aquiles nu e desarmado sobre os ombros. Apesar de Clítias ter particularizado os dois guerreiros e enriquecido a cena de significado e expressão, ele representou Ájax na pose Knielauf("movimentando ajoelhado"), que é, segundo Woodford, ambígua, pois pode sugerir estar Ájax tanto caminhando como levantando. Uma ambiguidade resolvida pelo Pintor de Frinos, ao mostrar Ájax correndo. ${ }^{9}$

As representações de Ájax com o corpo de Aquiles movimentando-se à direita tornaram-se raras e, no início da segunda metade do século VI a.C., o Pintor Exécias representou Ájax movimentando-se à esquerda, com Aquiles vestido de sua armadura sobre as costas. ${ }^{10}$ Não há mais nenhuma ambiguidade no movimento, Ájax já está, firmemente, caminhando. Os personagens não são designados por inscrições; um "atributo" de Aquiles,

7 WOODFORD, Susan; LOUDON, Margot. Two Trojan themes: the iconography of Ajax carrying the body of Achilles and Aeneas carrying Anchises in black figure vase painting. American Journal of Archaeology, v. 84, p. 25-40, 1980. Os vasos estão listados, conforme os grupos, em seu Apêndice I, como segue: A. Sozinhos: movimento à direita; B. Sozinhos: movimento à esquerda; C. Com Tétis; D. Com Tétis, guerreiro ou guerreiros (outro homem que Peleu); E. Com Tétis e Peleu; G. Com guerreiros somente (sem personagens feminino ou idoso); H. Com Tétis (?) e outra personagem feminina; e J. Outras representações.

8 O Grupo J engloba representações irregulares em comparação às anteriores, que se encaixam, todavia, em um ou outro dos dois contextos.

9 Cf. WOODFORD, S.; LOUDON, M., op. cit., p. 26-27.

10 Susan Woodford trata, detalhadamente, da questão dos possíveis significados dos movimentos à direita e à esquerda no Apêndice II. Para ela, o movimento à direita é apenas uma convenção antiga que continuou sendo adotada, e o movimento à esquerda foi criado pelo Pintor Exécias com a finalidade de pôr em evidência a armadura de Aquiles (WOODFORD, S.; LOUDON, M., op. cit., p. 39-40). 
contudo, torna a cena reconhecível: Tétis, sua mãe. ${ }^{11} \mathrm{O}$ Pintor Exécias pintou o mesmo tema, mas com Ájax e Aquiles sozinhos. Teoricamente, pode-se tomar essa cena como genérica, na qual qualquer par de nomes de heróis pode ser relacionado, mas a similaridade, segundo ela, do esquema com o do vaso anterior sugere que o pintor estivesse também pensando em Ájax e Aquiles. ${ }^{12}$

Essa primeira representação do Pintor Exécias introduziu, ainda, o segundo contexto, o familiar. Durante o último quartel do século VI a.C., a cena Ájax e Aquiles sozinhos (Grupos A e B) continuou sendo, frequentemente, representada; outros personagens, todavia, passaram a ser adicionados, colocando os dois heróis ora em um contexto, ora em outro. Nesse sentido, segundo Woodford, quando os pintores estão interessados no contexto familiar (Grupos C-F e H), eles mostram a figura de Tétis e, quando interessados no contexto da guerra (Grupo G), excluem as figuras da mulher e do idoso, para pôr totalmente o foco na batalha. ${ }^{13}$

Ao longo de sua análise, Woodford tece alguns comentários sobre a identificação dos personagens nos vasos sem inscrições, bem como sobre os momentos representados. Ela só tem certeza de serem Ájax e Aquiles quando Tétis está presente (Grupos C-F); fora isso, pode ser qualquer outro par de heróis. No grupo $\mathrm{H}$, ela não está totalmente convicta de ser Tétis uma das mulheres que flanqueiam o grupo central. Nos grupos E-F, ela entende ser o idoso o pai de Aquiles, Peleu. Quanto aos momentos, ela interpreta que, nos grupos C-D, Tétis está conduzindo o grupo central. No grupo E, o grupo central está sendo recebido, ora por Peleu, ora por Tétis. No grupo G, um arqueiro está, do mesmo modo que Tétis, conduzindo o grupo central. No contexto da guerra, Ájax pode estar levantando o corpo de Aquiles sobre os ombros.

Logo em seguida ao estudo de Woodford, Mary B. Moore abordou a iconografia de Ájax carregando o corpo de Aquiles a partir da obra do Pintor Exécias. ${ }^{14}$ Começa por ressaltar que se, por um lado, Ájax desempenha

11 Apoiada nessa ideia de atributo, Woodford entende que, quando Tétis está presente, é certo tratar-se de Ájax com o corpo de Aquiles, e que, na ausência dela, essa interpretação não é possível (WOODFORD, S.; LOUDON, M., op. cit., p. 27).

12 Cf. WOODFORD, S.; LOUDON, M., op. cit., p. 27.

13 Cf. WOODFORD, S.; LOUDON, M., op. cit., p. 28-30.

14 MOORE, Mary B. Exekias and telamonian Ajax. American Journal of Archaeology, v. 84 , p. $417-434,1980$. 
um papel essencial em alguns dos mais importantes episódios da Guerra de Troia, como o da luta pelo corpo de Pátroclo e o do resgate do corpo de Aquiles, por outro lado, há poucas representações desse herói nos vasos áticos, especialmente em figuras negras, que valorizam bastante as cenas épicas e heroicas. Nesse contexto, é que se destaca a obra do Pintor Exécias, uma vez ter sido o único a demonstrar especial interesse por Ájax. Duas representações que incluem Ájax, a cena do jogo de damas e a da luta pelo corpo de Pátroclo, aparecem, pela primeira vez, em sua obra; e os episódios de Ájax carregando o corpo de Aquiles e de seu Suicídio receberam, por parte desse pintor, um tratamento novo e único. ${ }^{15}$

Com a finalidade de destacar as inovações do Pintor Exécias, Moore apresenta, primeiramente, o tratamento dado a esse episódio por pintores anteriores. Inicia com Clítias, o primeiro pintor de vaso a representar essa cena, com Ájax levantando Aquiles em seus ombros, para levá-lo ao acampamento dos Aqueus, onde receberá os ritos funerários. Em seguida, examina os vasos dos pintores de Heidelberg e de Frinos, os quais representaram a cena com a mesma composição do Pintor Clítias: movimento à direita, com Aquiles $n u$ e desarmado. ${ }^{16}$

Analisa, então, dois dos primeiros vasos do Pintor Exécias, nos quais retomou esse tema, representando-o três vezes. A mudança mais significativa é a da direção do movimento, pois, nas três representações, Ájax se move à esquerda, com passos lentos, indicando a dificuldade devido ao peso do corpo de Aquiles. As composições variam, ainda, nos detalhes. Em todos os casos, os dois heróis estão vestidos e armados similarmente: quíton curto, couraça, elmo (com penacho característico), cnêmides e escudo chanfrado. Nas duas últimas representações, Ájax e Aquiles estão sozinhos; mas, na primeira, Exécias introduziu uma mulher, que, segundo a autora, deve ser Tétis. ${ }^{17}$

Constatando que a representação de Ájax carregando o corpo de Aquiles tornou-se muito frequente por volta de 530 a.C, época do Pintor Exécias, Moore examina dez vasos de outros pintores de figuras negras contemporâneos, para mostrar como trataram esse tema sob a influência

17 Cf. MOORE, op. cit., p. 425-429. 
dele. ${ }^{18}$ Para Moore, Ájax está, em todos esses casos, transportando o corpo de Aquiles para o acampamento dos Aqueus. Todavia, segundo ela, o Pintor Exécias introduziu, também, a representação de um momento anterior, o de Ájax retirando o corpo de Aquiles do campo de batalha. São poucas as representações desse momento e as duas conhecidas, ambas do Grupo de Leagro, são diferentes da de Exécias, uma vez que mostram um momento ligeiramente anterior ao seu, algo entre o levantamento e o carregamento. Na primeira, Ájax já ergueu o corpo de Aquiles do chão, mas ainda não o pôs sobre os ombros, e, na segunda, Ájax está ajoelhado já com o corpo de Aquiles nos ombros e prepara-se para levantá-lo. ${ }^{19}$

Em seu estudo sobre a iconografia de Ájax, Annelise Kossatz-Deissmann apresenta uma seleção de vinte e cinco vasos, nos quais entende representar-se a cena Ájax carregando o corpo de Aquiles para o acampamento dos Aqueus. ${ }^{20}$ Kossatz-Deissmann entende estarem essas representações conectadas tanto ao relatado na Etiopida de Arctino de Mileto quanto à Odisseia de Homero. O texto de Homero (Odisseia XXIV. 36-48) inclui Tétis e as Ninfas na cena, o que explica, segundo ela, a presença de uma ou mais mulheres nas cenas figuradas. ${ }^{21}$

O estudo mais recente e abrangente é o de François Lissarrague, ${ }^{22}$ que, por suas razões, prefere intitular essa iconografia de retorno do guerreiro morto. ${ }^{23}$ Mais uma vez é necessário ressaltar o caráter inovador de sua abordagem, voltada, acima de tudo, às questões de natureza histórica. Neste sentido, propõe-se a levar em conta o conjunto dos vasos conhecidos, com a finalidade de precisar a relação que mantêm, no interior das imagens, os diferentes atores. Em comparação com a série do armamento, na

18 As características básicas da influência de Exécias são: movimento à esquerda, impressão de peso e introdução de outros personagens.

19 Cf. MOORE, op. cit., p. 430-431.

20 KOSSATZ-DEISSMANN, Annelise. Achilleus. In: Lexicon Iconographicum Mythologiae Classicae. Volume I. Zürich; München: Artemis, 1981, p. 37-200.

21 Cf. KOSSATZ-DEISSMANN, A., op. cit., p. 185-191, 192-193.

22 LISSARRAGUE, François. L'autre guerrier. Arches, peltastes, cavaliers dans l'imagerie attique. Paris; Rome: La Découvert; École Française de Rome, 1990, p. 71-96. Ele analisa 100 vasos, listados no "Appendice", p. 94-96.

23 Lissarrague prefere, deliberadamente, nomear essa série de retorno do guerreiro morto. Chega mesmo a ventilar a possibilidade de tratar-se de Ájax carregando Aquiles, considerando serem ambos designados por inscrições nas imagens mais antigas e terem sido essas imagens, de alguma maneira, o protótipo que inspirou toda a tradição ática posterior. Opta, entretanto, por uma leitura metafórica das cenas em que o morto, anônimo, pode ser visto como um morto em combate, heroicizado (LISSARRAGUE, F., op. cit., p. 72-82) 
série do retorno, o jogo das tensões e das trocas entre categorias e espaços reencontra-se de maneira ainda mais clara. O espaço figurado, nesta série, tem um caráter de transição, uma vez tratar-se de acompanhar o morto para entregá-lo aos seus parentes. Trata-se, assim, de uma passagem do corpo ao cadáver; passagem em torno da qual as categorias, anteriormente definidas, idoso, mulher, arqueiro e hoplita, desempenham plenamente seus papéis. ${ }^{24}$

Esses papéis são revelados por meio da seriação, a partir das categorias que compõem o espaço figurado: o grupo central e os personagens secundários. O grupo central, constituído pelo carregador e pelo carregado, pode ser representado sozinho ou acompanhado de personagens secundários: divindades, personagens armados ou não armados. A orientação do grupo central é importante, mas não pelo fato de movimentar-se à direita ou à esquerda, e sim pelo lugar e pela atitude dos outros personagens em relação a ele: quando estão diante dele, podem precedê-lo ou acolhê-lo; quando estão atrás, segui-lo ou apartar-se. ${ }^{25}$

Concebendo a série dessa maneira, Lissarrague passa, então, à análise das categorias e dos espaços. Em sua concepção, são dois os espaços representados: o da guerra e o doméstico. O espaço da guerra é marcado pela presença exclusiva de personagens armados, enquanto que o doméstico, pela presença de personagens não armados. ${ }^{26}$

Principia pela presença discreta, mas importante, das divindades. Atena está presente em duas imagens. Na primeira, a deusa, usando elmo, evidencia o espaço guerreiro; mas, postada simetricamente à mulher, designa também a cidade em armas. É a ambiguidade cidade/lar que permite a presença de Atena nesse contexto. Na segunda imagem, localizada atrás do grupo central e voltada para o exterior da imagem, Atena marca o espaço da guerra. Hermes, do mesmo modo, aparece duas vezes. Na primeira, está em posição de acolhimento, marcando o espaço da guerra; na segunda, ele segue o grupo central, sendo acolhido por uma mulher, o que evidencia o espaço doméstico.

No espaço da guerra, há, segundo ele, duas representações distintas: cena de batalha e de guerreiros acompanhando o morto, em uma espécie

24 Cf. LISSARRAGUE, F., op. cit., p. 71.

25 LISSARRAGUE, F., op. cit., p. 82-85, lista os vasos como segue: Carregador/carregado (sem outro personagem); Presenças divinas; Carregador/carregado e personagens armados; Carregador/ carregado e personagens não armados; e Vasos fragmentários ou inéditos.

26 Cf. LISSARRAGUE, F., op. cit., p. 85-93. 
de desfile estático. Em algumas imagens, o grupo central é flanqueado por dois arqueiros, que estão frequentemente gesticulando e correndo. De todos os personagens que acompanham o morto, o arqueiro é, depois da mulher, o mais frequente, pois partilha com ela duas características essenciais: sua mobilidade e sua gestualidade. Assim, é comum dois arqueiros flanquearem o grupo central, como acontece com duas mulheres, mas jamais dois idosos, e raramente dois hoplitas.

A mulher está sempre presente nas combinações com personagens não armados, o que indica ser essencial seu papel. Quando um único personagem acompanha o grupo central, é uma mulher. Ao invés de tomar essa mulher como Tétis, mãe de Aquiles, Lissarrague prefere ler metaforicamente como mãe do morto, pois, frequentemente, em outros casos, aparece em combinação com um idoso. Seja qual for a relação da mulher com o morto, sua presença inscreve a cena no espaço doméstico. Estando associados uma mulher e um idoso em torno do grupo central, há duas situações: quando o idoso está diante do grupo central em posição de acolhimento e a mulher atrás, os dois estão imóveis; sendo o inverso, a mulher diante do grupo central em posição de acolhimento e o idoso atrás, este continua imóvel, enquanto ela se movimenta.

Nas combinações mistas, em que se encontram as categorias de armados e de não armados, há duas espacializações, dependendo se elas se misturam ou não em torno do grupo central, ou se o espaço é ou não polarizado em torno dele. Com dois personagens, o espaço é sempre polarizado, armados de um lado e não armados de outro. Quase sempre, um personagem não armado precede o grupo; sendo um personagem armado a preceder $\mathrm{o}$ grupo, trata-se de um arqueiro. A combinatória torna-se mais complexa quando há três personagens. O espaço continua, em geral, polarizado, com o personagem armado, frequentemente, atrás do grupo central, seguindo uma lógica linear da imagem: o corpo do morto deixa o espaço da guerra em direção ao doméstico. Todavia, por vezes, as categorias se misturam e, nesse caso, o personagem armado suscetível a entrar no espaço doméstico é o arqueiro. O arqueiro desempenha, assim, um papel importante, pois é o personagem que dispõe de maior mobilidade na imagem, ocupando todos os lugares em torno do grupo central, ou seja, seguindo, precedendo ou acolhendo o grupo central. 
Lissarrague finaliza seu estudo ressaltando que o espaço reunido pelo guerreiro carregador do herói morto em combate não é algo indefinido; muito ao contrário, trata-se da paisagem da cidade delimitada por personagens que mantêm relações entre si: mulher, idoso, guerreiro, arqueiro. A mobilidade e as posições desses diferentes personagens evocam a cidade, uma cidade una e solidária ao guerreiro morto em batalha. ${ }^{27}$

\section{Análise iconográfica}

Com outra preocupação, a de verificar as possíveis relações dessa iconografia com a tradição literária, retomo as questões colocadas pelas pesquisas anteriores sobre a identificação dos personagens e dos momentos representados, porém, com a finalidade de inseri-las em uma nova concepção dos esquemas iconográficos.

A cena de Ájax carregando o corpo de Aquiles na pintura da cerâmica ática ${ }^{28}$ varia na composição conforme o tempo das ações e do espaço onde estas se realizam. A temporalidade das ações é indicada pelas posturas do carregador: Ájax pode estar retirando, carregando ou chegando com o corpo de Aquiles. A espacialização é demarcada pela presença ou não de personagens secundários: estando envolvidos apenas guerreiros, as três etapas podem ser representadas, indo do campo de batalha ao acampamento, $\mathrm{e}$, havendo personagens não guerreiros, apenas a etapa final, a chegada à casa.

Isso implica quatro esquemas iconográficos distintos. No esquema I, Ájax está retirando o corpo de Aquiles do campo de batalha. Ájax e Aquiles podem estar sozinhos (IA ${ }^{29}$ ou acompanhados de outros guerreiros (Iв). ${ }^{30}$ No esquema II, Ájax está transportando o corpo de Aquiles. Eles

27 Cf. LISSARRAGUE, F., op. cit., p. 93.

28 A iconografia de Ájax carregando o corpo de Aquiles conta com uma centena de vasos, sendo que a maioria deles pode ser consultada em GRILLO, José Geraldo Costa. A Guerra de Tróia no imaginário ateniense: sua representação nos vasos áticos dos séculos VI-V a.C. 2009. Tese (Doutorado em Arqueologia) - Museu de Arqueologia e Etnologia, Universidade de São Paulo, São Paulo. Disponível em: $<$ http://www.teses.usp.br/teses/disponiveis/71/71131/tde-13042009-164013/>. Acesso em: março, 2012, p. $336-424, \mathrm{n}^{\mathrm{os}} 160-248$.

29 Cf. GRILLO, J. G. C., op. cit., cat. n ${ }^{\circ s} 160 \mathrm{~A}-\mathrm{B}, 225,231,246$ e 248.

30 Cf. GRILLO, J. G. C., op. cit., cat. nos 165, 193, 199, 214, 218, 224, 229, 232 e 235. 
podem, igualmente, estar sozinhos (IIA) ${ }^{31}$ ou acompanhados de outros guerreiros (ІІв). ${ }^{32}$ No esquema III, Ájax está chegando com o corpo de Aquiles ao acampamento. Nessa chegada, eles podem ser recebidos por um arqueiro (IIIA) ${ }^{33}$ ou por um hoplita (IIIB). ${ }^{34}$ No esquema IV, Ájax está chegando com o corpo de Aquiles à casa. Aqui, eles pode ser recebidos por um idoso $(\mathrm{IVA})^{35}$ ou por uma mulher $(\mathrm{IVB}){ }^{36}$

Apenas seis trazem inscrições nomeando os personagens. Todavia, não há motivo forte para se pensar em outra cena que na de Ájax carregando o corpo de Aquiles; pelo contrário, dos vasos conhecidos com essa composição, somente eles são nomeados por inscrições, e, na falta delas, a história de Aquiles, pelo lugar que ocupa na tradição épica, é a mais natural de vir à mente. ${ }^{37}$

O Pintor Clítias iniciou o esquema I, a retirada do campo de batalha, bem como o motivo de Ajax e Aquiles sozinhos (IA) nessa situação. Em todos os casos, Ájax está levantando nas costas o corpo de Aquiles; no último, do Pintor Dúris, Ájax parece estar apoiando-se em sua lança para facilitar o levantamento.

Apesar de o Pintor Clítias ter realizado a representação mais antiga, cerca de 570 a.C., o Pintor Exécias foi o primeiro, entre 540 e 520 a.C., a conceber o conjunto das ações: retirando, transportando e chegando. Ele iniciou o esquema Iв, em que Ájax e Aquiles estão acompanhados de outros guerreiros. A maioria das ações se dá no contexto da luta pelo corpo de Aquiles, na qual os outros guerreiros combatem na retaguarda de Ájax, para permitir sua retirada. Em um único caso, o contexto da retirada do campo de batalha é indicado por um guerreiro caído, pelo qual passam Ájax e Aquiles. Nessas ações, Ájax pode estar: a) levantando Aquiles do chão, b)

31 Cf. GRILLO, J. G. C., op. cit., cat. $\mathrm{n}^{\text {os }}$ 161, 162, 163A-B, 170, 171, 172, 173, 174, 177A-B, $178,186,202,203,211,231$ e 247.

32 Cf. GRILLO, J. G. C., op. cit., cat. no 196.

33 Cf. GRILLO, J. G. C., op. cit., cat. $\mathrm{n}^{\text {os }} 188,233$ e 234

34 Cf. GRILLO, J. G. C., op. cit., cat. no 245.

35 Cf. GRILLO, J. G. C., op. cit., cat. nos 164A, 180, 184, 198, 201, 204, 209, 213 e 219.

36 Cf. GRILLO, J. G. C., op. cit., cat. nos 166 (veja-se a Figura 1 no final do texto), 168, 175, $176,181,182,183,185,187,189,190,191,192,195,197,205,206,207,210,212,216,217,220,221$, $222,223,226,227,228,230,236,238,240,241,242,243$ e 244. Além desses quatro esquemas, há oito vasos que apresentam outras representações (Cf. GRILLO, J. G. C., op. cit., cat. nos 164B, 167, 179, 194, 208, 215, 237 e 239) e dois nos quais elas são incertas (Cf. GRILLO, J. G. C., op. cit., cat. nos 169 e 200).

37 Para as referências detalhadas da argumentação a seguir, cf. GRILLO, J. G. C., op. cit., p. $137-144$. 
levantando Aquiles nas costas, c) com Aquiles já posto em pé e amparado nos braços, e d) já retirando Aquiles nas costas.

O esquema II, Ájax transportando o corpo de Aquiles, bem como o motivo dos dois sozinhos (IIA), foi iniciado pelo Pintor de Heidelberg. Nessa situação, Ájax, já com Aquiles nas costas, pode estar: a) correndo, ou b) caminhando. O primeiro motivo foi iniciado, também, pelo Pintor de Heidelberg, no qual Ájax está sempre correndo à direita; o segundo, pelo Pintor Exécias, com Ájax, geralmente, caminhando à esquerda, exceto na ânfora do artista da Classe da Coleção das Medalhas 218, na qual ele caminha à direita. $\mathrm{O}$ esquema ІІв foi criado e usado exclusivamente pelo artista Maneira de Lisípides. Nessa representação, Ájax, seguido por um Hoplita, está caminhando à direita.

O Grupo de Leagro foi o criador, por volta de 520 a.C., do esquema III, em que Ájax está chegando com o corpo de Aquiles ao acampamento, bem como do motivo do recebimento por um arqueiro (IIIA). Anos mais tarde, entre 500 e 490 a.C., o Pintor de Michigan pintou esse motivo em duas ânforas da Classe da Faixa com Pontos, classe de ânforas pequenas com conexões com o Grupo de Leagro. Nos três casos, ocorrem representações com quatro personagens, em que o grupo central movimenta-se $\grave{a}$ esquerda e está flanqueado por arqueiros. No mesmo período, entre 500 e 480 a.C., um artista anônimo criou o esquema IIIB, em que Ájax e Aquiles são recebidos por um hoplita. Trata-se de um desenvolvimento do esquema anterior: o grupo central movimenta-se, também, à esquerda, mas está flanqueado por dois pares de hoplita e arqueiro.

O esquema IV, em que Ájax está chegando com o corpo de Aquiles à casa, foi criado na mesma época, cerca de 540 a.C., por dois artistas, o Pintor do Camelo e o Pintor Exécias. O Pintor do Camelo iniciou o esquema IVA, em que Ájax e Aquiles são recebidos por um idoso. Em todas as composições, o grupo central movimenta-se à esquerda e, por isso, o idoso o recebe sempre nesse lado. As composições variam segundo o número de personagens envolvidos. Quando há cinco personagens envolvidos, o grupo central está flanqueado pelo idoso e um par formado por arqueiro e jovem ou por hoplita e arqueiro; havendo quatro personagens, flanqueiam o grupo central o idoso e um arqueiro, ou o idoso e uma mulher. 
O Pintor Exécias iniciou o esquema IVB, em que Ájax e Aquiles são recebidos por uma mulher ${ }^{38}$ Nessas composições, o grupo central movimenta-se, na maioria das vezes, à esquerda, e, por vezes, à direita; a mulher que o recebe aparece, assim, tanto numa como noutra posição, sem que se estabeleça um padrão. As composições variam, como no esquema anterior, segundo o número de personagens envolvidos. Quando há três personagens, a mulher está sozinha recebendo o grupo central. Havendo quatro personagens, a mulher flanqueia o grupo central com vários outros personagens: outra mulher, um hoplita, um arqueiro, o deus Hermes e um idoso. Com cinco personagens, a mulher pode estar: a) à esquerda, sozinha, com hoplita e arqueiro à direita ou com arqueiro e idoso; b) à direita, acompanhada de um homem, com arqueiro à esquerda, ou acompanhada de um arqueiro, com outro arqueiro à esquerda. As composições com seis personagens são as menos padronizadas; os únicos elementos repetitivos são: o grupo central sempre flanqueado por dois personagens de cada lado e a mulher sempre acompanhada. São apenas quatro casos: nos três primeiros, ela está à esquerda e, no último, à direita. Ela pode estar acompanhada de: um homem, com hoplita e jovem do outro lado; um arqueiro, com arqueiro e hoplita do outro lado; um idoso, com hoplita e arqueiro do outro lado; e uma outra mulher, com mulher e jovem do outro lado.

Existem cinco representações do esquema IV que são tanto diferentes das anteriores quanto entre si; não permitindo, assim, um agrupamento. Nessas outras representações, o grupo central movimenta-se à esquerda e pode ser recebido por: a) um jovem, com um arqueiro e a deusa Atena do outro lado; b) um homem, com uma mulher do outro lado, ou um homem sozinho; c) um hoplita, acompanhado de arqueiro e dois hoplitas, com uma mulher e dois hoplitas do outro lado; d) um arqueiro, com uma mulher ou com um idoso do outro lado; e) uma mulher, com um carro e um hoplita entre ela e o grupo central. Há, ainda, outra representação em que o grupo central movimenta-se à esquerda e é recebido pelo deus Hermes, com um hoplita do outro lado. Trata-se de uma cena de chegada, mas não há como determinar o local da mesma, que pode ser tanto o acampamento (esquema III) quanto outro lugar qualquer. 
Devido ao estado fragmentário dos vasos, duas representações permanecem incertas. No primeiro, um fragmento de cálice de um artista anônimo, aparecem apenas partes de Ájax, perna esquerda e escudo chanfrado, e de Aquiles, braço direito, cabeleira e escudo chanfrado, voltados à direita. A posição da perna de Ájax ainda levemente flexionada e a do braço de Aquiles com a mão rente ao chão permitem supor que Ájax está acabando de levantar o corpo de Aquiles, o que inscreveria esse vaso no esquema IA. No segundo, uma enócoa fragmentária do artista da Classe de Altemburgo, aparecem apenas as partes superiores de quatro personagens: Ájax e Aquiles movimentando-se à esquerda, e uma mulher à direita, acompanhada de um arqueiro. Não é possível, portanto, determinar quem recebe o grupo central; a presença da mulher, entretanto, indica que é uma cena de chegada à casa.

O grupo central é composto de Aquiles, o carregado, e de Ájax, o carregador, o qual é representado sozinho em quase um quarto dos casos; entretanto, na maioria das vezes, ele está acompanhado de personagens secundários, que podem ser: a) guerreiros: arqueiro e hoplita; b) divindades: Atena e Hermes; c) não guerreiros: idoso, mulher, jovem, homem e outra mulher.

A representação dos personagens guerreiros é bastante equilibrada; pois, arqueiro e hoplita são representados vinte e cinco vezes cada um, aparecendo em quarenta e quatro ${ }^{39}$ dos oitenta e nove vasos. As divindades também têm representação balanceada, apesar de aparecerem poucas vezes. Entre os personagens não guerreiros, o idoso e a mulher estão em destaque. $\mathrm{O}$ idoso é representado nove vezes e a mulher trinta e seis. Eles jamais são designados por inscrições; não estão, todavia, no anonimato absoluto, pois aparecem em correspondência com Peleu e Tétis, nas cenas de armamento e de partida, são o pai e a mãe do guerreiro morto. ${ }^{40} \mathrm{~A}$ outra mulher também tem representação expressiva, oito vezes; já o jovem e o homem são pouco representados, quatro vezes cada um.

Os gestos realizados pelos personagens não guerreiros são variados, porém, recorrentes. O idoso aparece, na maioria das vezes, inerte; algumas vezes realiza um gesto que acompanha a emissão da palavra e, em outras, tem a mão na cabeça. A mulher aparece, na maioria das vezes, realizando

39 Em seis casos, eles são representados no mesmo vaso (Cf. GRILLO, J. G. C., op. cit., cat. $\mathrm{n}^{\text {os }} 182,183,185,201,217$ e 245).

40 Cf. GRILlO, J. G. C., op. cit., p. 55-74. 
um gesto que acompanha a emissão da palavra ${ }^{41} \mathrm{e}$, em outras, ela pode estar balançando os braços, com os braços envoltos ou ter a(s) mão(s) na cabeça, no peito, envolta pelo manto. O jovem está sempre inerte. Das quatro vezes em que o homem é representado, em uma realiza um gesto que acompanha a emissão da palavra, e, nas outras, está inerte. A outra mulher só aparece nas cenas em que flanqueia o grupo central com a mulher, mãe do guerreiro. Quando está parada, pode realizar um gesto que acompanha a emissão da palavra, ter a(s) mão(s) na cabeça, no peito, ou envolta pelo manto.

\section{Considerações finais}

A análise iconográfica evidencia que todas as categorias da sociedade ateniense, são representadas, guerreiros e não guerreiros; todavia, são os papéis do idoso e da mulher, pai e mãe do guerreiro, que se destacam.

O grupo central pode ser recebido por guerreiros, hoplita e arqueiro, quando a chegada dá-se no acampamento, mas é na chegada à casa que as representações concentram-se. O idoso o recebe muitas vezes; é a mulher, todavia, que o faz com mais frequência. $\mathrm{O}$ idoso, quase sempre, está inerte. Em alguns casos, ele participa, realizando um gesto que acompanha a emissão da palavra. Entretanto, é a mulher que tem uma participação mais expressiva. Ela raramente está inerte; pelo contrário, normalmente, está movimentando-se e gesticulando.

Como na cena da partida, a mulher gesticula com a mão envolta pelo manto. Se, no contexto da partida, esse gesto significaria um pedido de proteção para o filho que parte para a guerra, no de retorno seria a precaução para o êxito dessa última passagem e para que o morto não retorne ao mundo dos vivos; daí a presença de Hermes Psicopompo. O gesto que a mulher mais realiza, e que a torna proeminente, é o que acompanha $a$ emissão da palavra. ${ }^{42}$

41 Cf. GRILlO, J. G. C., op. cit., cat. nos 166 (veja-se a Figura 1 no final do texto), 167, 168, 184, 194, 205, 207, 209, 212, 217, 220, 221, 223, 227, 228, 236, 238, 241, 242 e 243.

42 Cf. GRILlO, J. G. C., op. cit., cat. ${ }^{\text {os }} 166$ (veja-se a Figura 1 no final do texto), 167, 168, 184, 194, 205, 207, 209, 212, 217, 220, 221, 223, 227, 228, 236, 238, 241, 242 e 243. 
A pintura de Exécias na ânfora conservada no Museu Pérgamo em Berlim, na Alemanha, oferece um excelente exemplo desta representação (Figura 1). Vindo da direita (pé esquerdo à frente e o direito com o calcanhar já levantado, indicando o início de um novo passo), um guerreiro, completamente armado (elmo, couraça, chiton curto, cnêmides, escudo chanfrado e lança), caminha para a esquerda carregando, em suas costas, o corpo de Aquiles morto e igualmente trajado, mas sem a lança. Vindo da esquerda (pé esquerdo à frente e o direito com o calcanhar já levantado, indicando o início de um novo passo), uma mulher, vestindo chiton longo, recebe-os com gesto que acompanha a emissão da palavra (braço esquerdo levantado e com palma da mão para cima e braço direito estendido para frente).

Os personagens não são nomeados por inscrições; porém, considerado no conjunto da série desta cena, podemos pensar no grupo de Ájax carregando Aquiles, sendo recebido por Tétis, a mãe de Aquiles. Seja como for, uma mulher recebe o grupo central. Ela representa o contexto da casa para onde o morto está sendo levado; contexto, portanto, da cidade, na qual o uso da palavra é um direito seu.

Mulher e idoso, representantes maiores dos não guerreiros, indicam que a guerra não é assunto exclusivo dos guerreiros, mas sim de toda a cidade. Nesse sentido, a mulher, pelo destaque lhe é dado nessas pinturas, participa da vida da polis ateniense como uma autêntica cidadã, ainda que num plano diferenciado do masculino. Pois, como afirma Alain Schnapp, "a profusão de imagens que investem na superfície dos vasos não é o resultado de um acidente quase fotográfico, de um milagre improvável, mas a manifestação de atenção, de uma atitude coletiva, de uma necessidade social. As imagens são esta parte ideal da cidade pensada pelos gregos, para os gregos". ${ }^{43}$

Recebido em março de 2012. Aprovado em abril de 2012.

43 SCHNAPP, Alain. Des vases, des images et quelques uns de leurs usages sociaux. Dialoghi di Archaeologia, v. 3, p. 69-75, 1985. Citação da p. 75. 


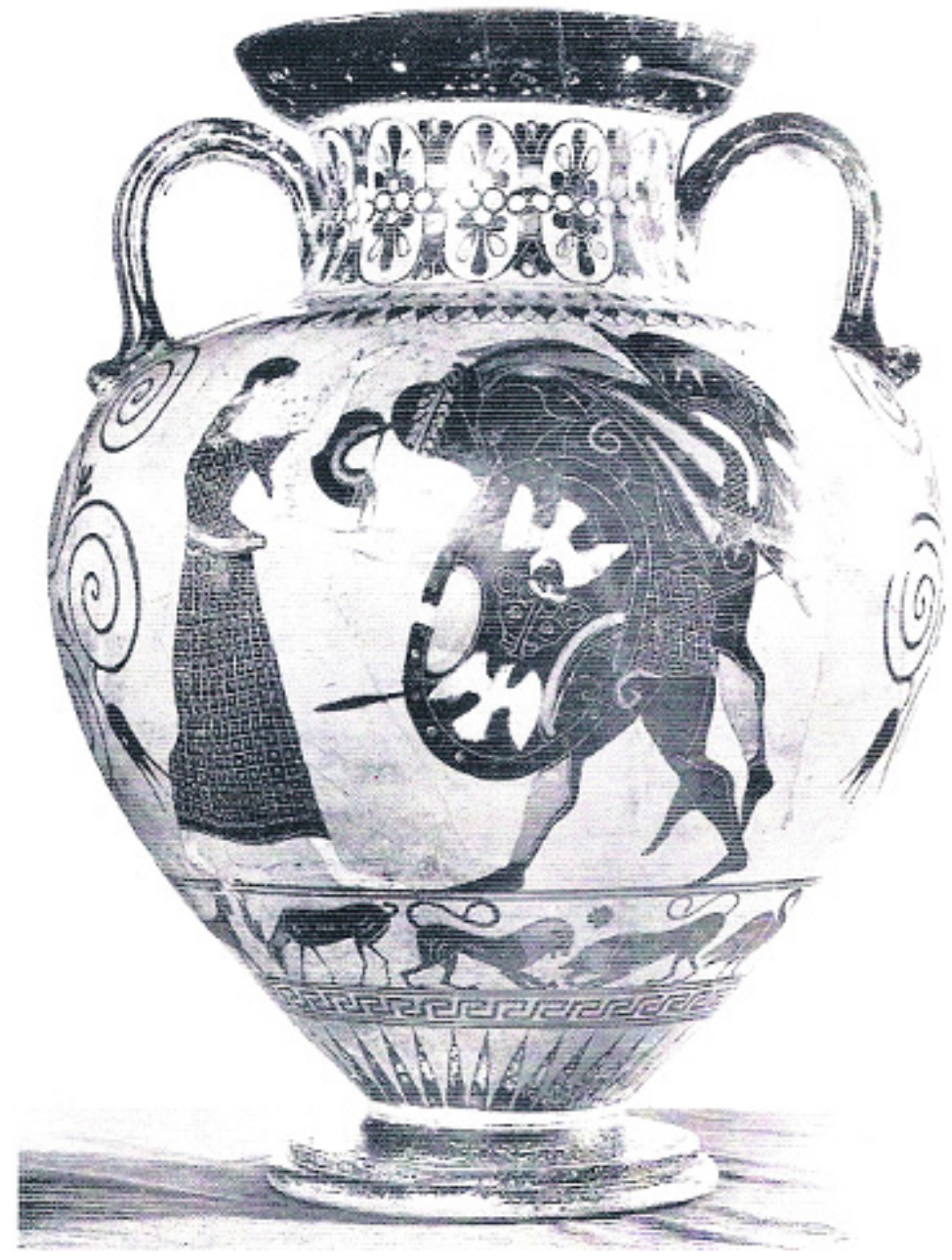

FIGURA 1 - ÂNFORA. FIGURAS NEGRAS. PROV.: CHIUSI. ATR.: PINTOR EXÉCIAS. BERLIM, MUSEU PÉRGAMO, COLEÇÃO DE ANTIGUIDADES, INV. F1718. CERCA DE 540 a.C. 